\title{
The Use of Activity Theory as a Methodology for Developing Creativity within the Art and Design Classroom
}

\section{Victoria Kinsella}

\section{ABSTRACT}

This article discusses the use of an activity theory system as an analytical tool within the school art and design classroom. It highlights reasons for its use and makes explicit its importance for investigations into teaching and learning. It proposes that through an activity theory system, teachers and researchers are enabled to reflect on the formation of thought and develop an understanding of pedagogy, where classroom roles, rules and participation are made visible. The article draws on primary research which explores the development of creativity within the English Key Stage 3 (age 11-14) art and design classroom. Illustrations are provided to show how through the use of an activity theory system a multilayered analysis took place. This generated reflection on relationships and structures within and surrounding the classroom, impinging creative activity. Through using the activity theory system teachers and researchers were enabled to observe the complexity of the classroom and question socioculturalpolitical structures which empowered change.

\section{KEYWORDS}

\section{Activity theory, creativity, identity, learning, secondary education, teaching}

\section{Introduction}

Research concerning art and design teaching and learning needs an analysis tool that takes into consideration the interconnected elements of the culture and structure of the classroom environment, and the relationship to formations of mind and action. The varied skills, creative processes and behaviours present in the classroom involve a range of interconnected interactions. The classroom is a multifaceted environment, where individual identities, dispositions, social and historical perspectives and pedagogical processes exist. Because of these complexities, a methodology that accounts for individual realities but also attributes collective understanding is needed. This methodology must consider how learning takes place, and its relationship to wider socio-cultural elements that shape teaching and learning. I propose activity theory (AT) (Engestrom€ et al. 1999) as an analytical methodology that provides a lens to explore these interactions together with cognition.

In this article, I shall reflect on four case studies from a research project exploring the development of creativity within the English Key Stage 3 (age 11-14) art and design classroom. It draws on results from a study in England, where art and design teachers explored the development of creativity over a six-week period. Significantly, this research utilised an AT system to deconstruct the creative process, and focus on the ways in which teachers negotiated their creative teaching approaches in light of performative and accountability challenges. 


\section{Creativity}

In the last 30 years there has been a re-emergence and re-emphasis on creativity in education policy. The economic shift in market demands for creative knowledge emphasised the necessity to reconstruct education, as Seltzer \& Bentley $(1999,9-10)$ state:

To thrive in our economy defined by the innovative application of knowledge, we must be able to do more than absorb and feedback information. Learners and workers must draw on their entire spectrum of learning experiences and apply what they have learned in new and creative ways.

The creative classroom rhetoric became a focus for researchers who wanted to investigate questions about the connections between knowledge and creativity within an increasingly regulated and monitored curriculum (Beetlestone 1998; Starko 2005; Jeffrey 2004). Moving away from the academic theories of a psychological mind and culture, researchers began to question the application and acquisition of creativities within the classroom. The NACCCE (1999) report highlighted the need for a creative pedagogy. However, research into creative teaching and learning had been developed previous to the NACCCE report by Woods \& Jeffery (1996), Craft et al. (1997) and Harland et al. (1998), who had distinguished between creative teaching (creativity in pedagogy) and teaching for creativity (with a focus on the development of creativity in the learner). Jeffery \& Woods (2003) analysed the nature of creative teaching and the effects on learners. Their research outlined that the relationship between teaching creatively and teaching for creativity was integral, where one is inherent in the other. This was further acknowledged within the NACCCE $(1999,90)$ report, which states: 'Teaching for creativity involves teaching creatively... Young people's creative abilities are likely to be developed in an atmosphere in which the teacher's creative abilities are properly engaged'.

Recently, policy has recognised that in order to develop creative knowledge, its value needs to be endorsed through education. In the independent review of Cultural Education in England, Henley (2012) asserts that 'no education can be complete, indeed no program of education can even begin, without making the arts and creativity central to a child's life'. These discourses maintain the importance of arts education and creativity for offering young people vital cultural experiences as part of a broad and balanced curriculum. However, these discourses contrast significantly with the continuing audit culture where arts and creativity are omitted. In November 2010, the Schools White Paper The Importance of Teaching (DfE 2010) set out its intentions for the future of the English education system, stating it would reform performance tables and set high expectations. This became the main feature of the government's drive to support the English Baccalaureate (EBacc). The EBacc features as a measure in school league tables, which quantify whether a learner has secured good GCSE passes, grade C and above, in English, Mathematics, the Sciences, a Modern Foreign Language and a Humanities subject such as History or Geography. These specific subjects were identified as 'facilitating subjects' for future entry into higher education and a job (Russell International Excellence Group 2011). The exclusion of the arts from these options devalued their position as academic subjects. This omission and challenges posed by school assessment and performativity measures can be viewed as being indicative of discrimination against creative and cultural forms of intelligence. 


\section{Performativity and accountability}

A fundamental issue linked to the development of creativity within the art and design classroom are pressures assigned to teachers under performative regimes. These accountability measures function as policy epidemics. Input to output modes of accountability and evidence govern teacher pedagogy and learner experience. Pedagogy is challenged by the 'terrors of performativity' (Ball 2003, 1) and real innovation and creativity disrupted. Turner \& Bisset $(2007,195)$ state that due to these factors 'teachers compromise on the kinds of teaching in which they believe in, and the kinds of teaching demanded by performativity' or, as Butler $(1990,136)$ has described, they create and live within 'an enacted fantasy'. Time given to art and design in the English KS3 system is also decreasing. Therefore, teacher reflection in and on learning is reduced and often non-existent. Without reflection, teachers cannot identify factors that impact teaching, account for different modes of learning, or personalised pedagogical approaches. This limits awareness of the culture and structures of the classroom which would enable them to pose challenging and critical questions, transforming practice.

Whilst trying to raise standards with the increase of accountability, educational discourse has continued to highlight the importance of creativity in education. How teachers balance both performativity and creativity is questionable. Maisuria (2005) claims that teachers are faced with a dualism, on one hand they are encouraged to be innovative and foster creativity, whilst also being subject to accountability. Teachers are therefore required to go beyond the safe and known, take risks, be innovative and rethink their approaches in order to develop creativity within the classroom.

\section{Research aims}

Pedagogical practices with a focus on developing creativity, whilst adhering to the standards agenda, are complex. The idea of 'rebalancing pedagogy' suggested by Burnard \& White $(2008,676)$ suggests that teachers need to be given the opportunity to navigate and be supported through opposing demands of performativity and creativity. This requires confident teachers to transform their own practice and that of their pupils. This has also been highlighted by Steers $(2010,31)$, who states that 'creative pupils need creative teachers with the confidence to take creative risks'. If this is the case, there needs to be a reinvigoration of the teachers' personalised creativity alongside reflection in and on classroom cultures and structures.

This article reports on the results from a research study in England, which aimed to address a number of these issues. The research aimed to:

- research and evaluate new approaches to creative teaching and learning;

- analyse, explore and offer insights into issues surrounding creativity within the Key Stage 3 art and design classroom utilising an AT system;

- develop new modes of creative practice that address current challenges for art and design teachers. 


\section{Methodology}

The participants for the research comprised four art and design teachers from different departments based in the English Midlands. One teacher was chosen, $n=c 4$ teachers, and one KS3 class, $n=c 28$ learners. The research aimed to address the issues of creativity in the classroom through a time-delineated (sixweek) intervention where the teachers were encouraged to reflect in and on creative practice.

Researching creativity in the complexity of the classroom environment required not just one way of knowing and valuing, but methods that took into account diversity and difference (Greene et al. 2001). Teachers were therefore encouraged to reflect on practice through questionnaires, lesson reflections and interviews. The questionnaire was designed to probe teachers' opinion of creativity and their educational and teaching history. Questions were focused on the secondary curriculum, previous educational experiences and teaching career.

Lesson reflections took place in the teacher's classroom after the delivery of their lesson. A semistructured approach was utilised which aimed to eliciting teacher perceptions of creative teaching, teaching for creativity and creative learning. Schon $(1983,68)$ identified reflective practice as 'reflection on and in action', where inquiry is focused on the practice of teaching and activity. This was important for this research where the teachers were encouraged to implement new teaching approaches. Semi-structured interviews were conducted at the end of the six weeks. Questions for the interviews focused on exploring creative teaching and learning and the use of an AT system as an analytical tool.

For this article, I shall focus on the data collated from the interviews and post-lesson reflections as they highlight key information for the use of AT in the art and design classroom.

Prior to collecting data, this research was ethically considered. All participants were informed of the research aims via a consent form and were offered confidentiality and anonymity. The research was approved by an ethics board to ensure it trustworthiness.

\section{Activity theory as an analytical approach}

In order to deconstruct teaching and learning, an AT system was used as an analytical lens. For this research it was important to recognise that creative activity was not an individual pursuit but embedded within the complex socio-cultural-political classroom. This space accounts for different identities, intelligences, modes of learning and pedagogical processes. The activity system also embraces individuality and interconnections. Therefore, such a perspective includes not only an understanding of social and cultural structures, but dispositions, values and discourses. Attention could be paid not only to creative teaching and learning but to structures surrounding the classroom.

First-generation activity theory

Investigation into individual learning mediated by cultural artefacts and membership of a group within a wider community began with the work of Vygotsky (1978). Vygotsky established a triangular model of action, which explored the relation between human behaviour and mediation. This model explored the 
process through which human behaviour is mediated by artefacts that prompt action (Bakhurst 2009, 199). Within the classroom, these artefacts include physical tools, such as a paint brush, or of the mind, such as language via questioning or discussion. These artefacts form a stimulus between the individual and an outcome. The concept of internalisation is central to Vygotsky's model, whereby an individual intervenes and interacts with the artefact, enabling change within the culture (Burnard 2007). Vygotsky's model of action is represented diagrammatically in a triangle format, as shown in Figure 1. In this figure, the subject is the individual, who interacts with the mediating artefact, enabling him or her to arrive at the object, which is the outcome of learning. The artefact is the central component that becomes the stimulus affecting practice.

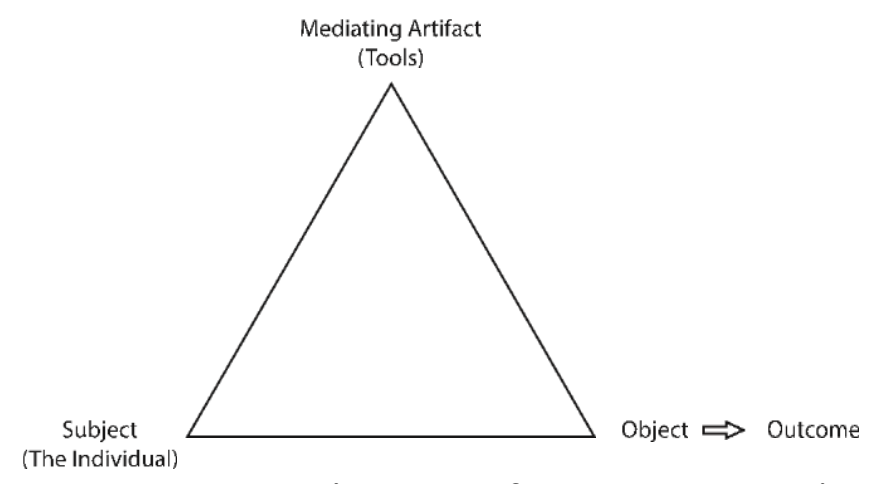

Figure 1. Vygotsky's model of mediated action (1978)

Leont'ev (1978) recognised constraints in Vygotsky's concept of action and the singular focus on individual action, not grounded in an understanding of the social structures which impact on the activity. The Leont'evian perspective therefore attributes a collective motivation to transform an object into a desired outcome and the importance of the social formation of knowledge as a key component to discovery (Blin \& Munro 2008). For explorations in the classroom, the acknowledgment of socially constructed knowledge is important and a key component of teaching and learning.

Second-generation activity theory

Engestrom (1999) also sees the study of artefacts as an important aspect to human functioning.€ However, according to Engestrom (1999), the Vygotskian (1978) and Leont€ 'evian (1978) perspectives did not attribute socially distributed, as well as the importance of artefact-mediated or cultural aspects of human action. Engestrom therefore looked at the process of activity further, and devel- $€$ oped an activity system that allowed both individual learning processes and social interaction to be viewed simultaneously (Figure 2).

Therefore, Engeström's model of an activity system adds an additional layer to the Vygotskian model of action, placing the activity within a social context. In the upper part of the figure, Engestrom presents a Vygotskian conception, that the€ 'object' of an action by (or on) a 'subject' is culturally 'mediated' by some form of 'artefact'. This model is extended in the lower part of the figure to encompass both individual and group actions in a collective, interactive activity system in which 'rules', a sense of 
'community' and 'division of labour' are evidenced. By identifying the socio-cultural-political components of an activity, interrelationships between the individual and the community can be evidenced. Moreover, by expanding the model to include, the rules, community and division of labour, an activity within the classroom can be better understood and analysed.

\section{Activity theory analysis}

In order to highlight the potential of AT as an analytical tool for use in the art and design classroom, I shall break down the socio-cultural-political constituents of the AT system. Through exploring each of the constituents of the AT system, analysis of how activity is taking place can be viewed in conjunction with individual cognition, socio-cultural-political and historical structures alongside cultural practice.

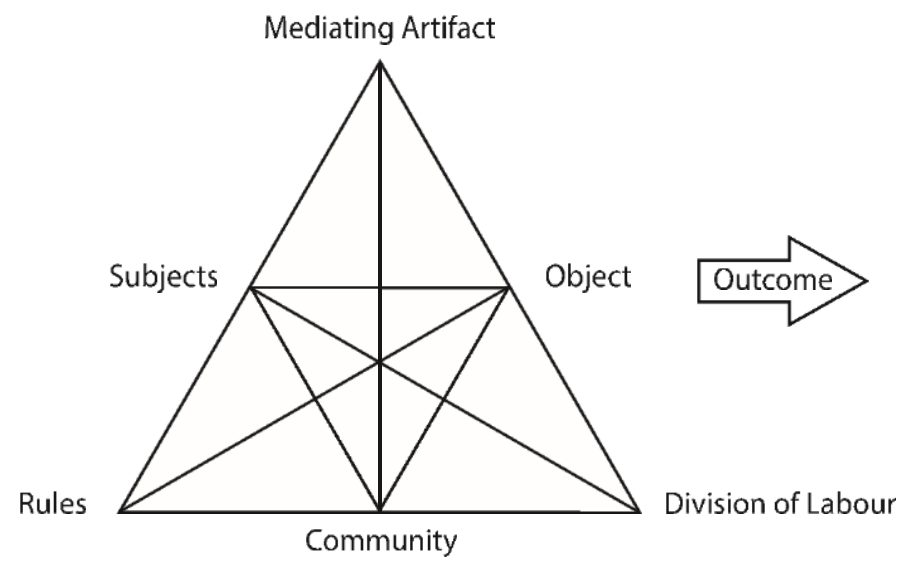

Figure 2. Engeström's structure of human activity system (1999)

Engestrom $(2001,7)$ recognised that participants in an activity system bring with them their own€ diverse histories. This means that the activity system will be multi-layered. For any investigation into teaching and learning, it is necessary to consider the educational histories that educators and learners come with into the classroom. Identity is pedagogised within educational practices and discourses. These norms create the viability of the subject and their ontology. Central to this identity construction is the acknowledgment of the cultural-historical character of subjectivity. Subjects constantly renegotiate their partiality in light of experiences. Being aware of the factors that impact subjectivity assists the illumination of the culture of the classroom. Therefore, activity systems take shape and are transformed over time, suggesting a concept of 'historicity' (Engeström 2001, 7).

In Figure 3 Engeström's (2001) model of an activity system has been interpreted to illustrate the components of an activity in terms of practices within the art and design classroom. By breaking down an activity into these distinct components key relations can be illustrated and interconnections can be observed. Deciphering the macro and micro characteristics that govern the classroom is an important part of analysing classroom activity. In the AT system, the socio-cultural-political aspect of activity is conceptualised through associations between rules, division of labour and community. Educational environments operate under specific rules, which shape activity. Rules are not only teacher directed but externally determined. Within schools these rules are governed by curricular, policies, performative and accountability measures. These discourses can often dominate practice and shape how activities are 
planned. Jackson et al. (1993) define rules as the 'dos and don'ts' of the classroom, which provide the teacher with guidelines for activity. The rules therefore can be seen as codes which regulate teaching and learning.

Alongside this, exchange within the activity system plays a crucial role in the development of a successful activity. How divisions of labour are constructed has an impact on the development of the community. Power relations are inherent in classroom situations, but are exemplified further in classrooms today due to status attributed to the rules of the classroom, such as performativity, and assessment regimes. These divisions are shared between teacher and learner, teacher directed or learner to learner. It is important to recognise that both the rules and division of labour bring into focus the character of the relationships which affect the socio-cultural environment. Dissecting the rules and divisions of labour can facilitate explorations into the community. Exploring the social and artistic practices that shape the classroom environment is a key element to creating a community that appreciates both individual and collaborative perspectives. At the heart of a successful learning community is the concept that human performance is not the action of the individual human mind, but groups of minds in interaction with each other and minds in interactions with tools and artefacts.

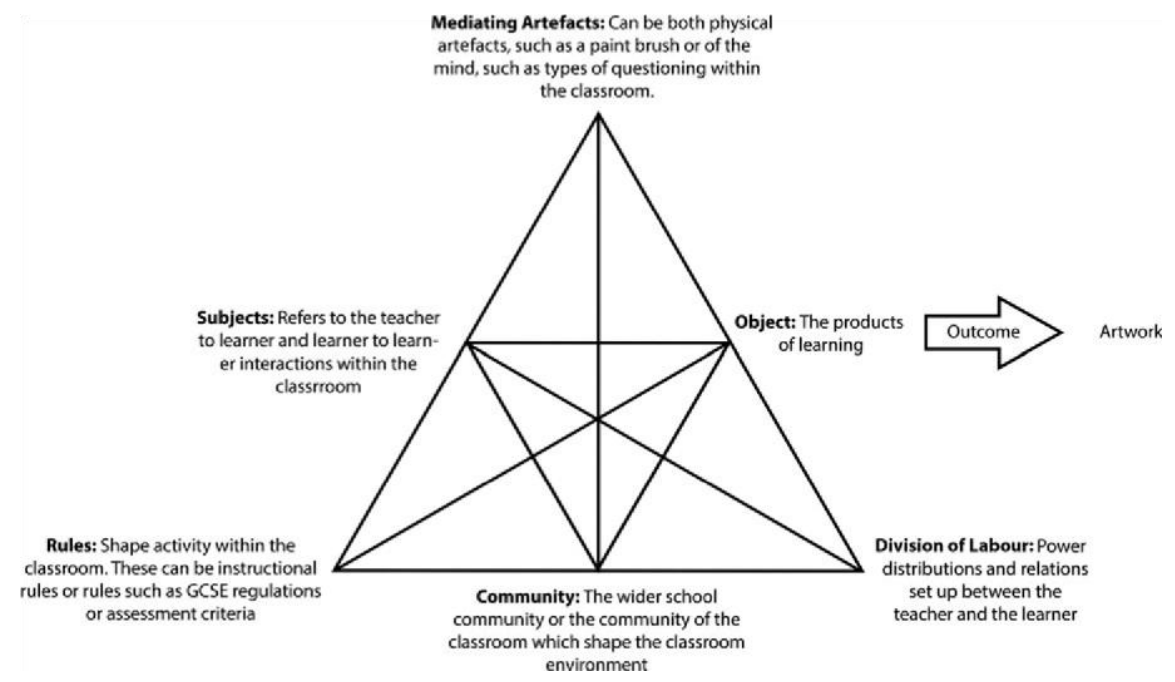

Figure 3. Activity system for the art and design classroom

Engeström et al. (1999) also believed that the object of activity shapes and determines the action. Within the classroom the object refers to the products and outcomes of learning. The construction of an object includes formation of a subject, community and cultural-historical elements surrounding the classroom. As the object plays a critical role in defining activity, research within the classroom should entail a deep understanding of its purpose and how it is mediated by and through artefacts. Through explorations of their purpose and effectiveness, pedagogical mechanisms can be refined. 


\section{Recognising creativity contradictions through the activity theory system}

Contradictions are characteristics that disrupt teaching and learning and are present in every activity system. By signifying them, emergent opportunities for development can occur. As activity is historically accumulated, contradictions can become embedded in practice and therefore be unchanged. It is therefore important to explore these contradictions, to question, challenge and reflect in order to transform activity. The AT system provided a way for the teachers in this research to understand their creative teaching and learning practices. Through analysis, creativity contradictions within the system were highlighted; these often presenting challenges, but also opportunities for change.

Through exploring each AT node, the teachers began to uncover their true concerns about the status of creative practice within the art and design classroom. These reflexive approaches became partly philosophical but also confessional (Geertz 1973). The process of zooming in and looking at the creative activities through an activity system lens helped depict core contradictions. The teachers highlighted three main contradictions that disrupted creative practice and pedagogy:

- teacher identity;

- the rules of the classroom, governed by school cultural expectations;

- the object as product, which are specified outcomes and objectives outlined through assessment.

The first of these contradictions regarded the teachers' own personalised notions of their identities as both teachers of art and design and practicing artists. The duality of these positions caused tensions within the classroom. As a teacher's identity is constantly being negotiated, it is influenced by many factors, ranging from the professional to the social. The teachers discussed how their identities as teachers but also as artists played a critical role in the identity contradictions caused within the classroom. They acknowledged limitations of exploring their own artistic practice as impinging on the development of a creative teaching pedagogy. The reasons identified by the teachers for this were school cultural and measureable expectations:

Because you don't get the chance to practise doing your own artwork. (Teacher 1)

Due to time constraints and work load I no longer create my own artwork. (Teacher 2)

The quotations highlight how the teachers negated their previous identities as artists, focusing instead on the professionalism of their role as teachers. This led to practice and pedagogy being focused on more generalist and outcome based approaches highlighted in this quotation:

There is teaching art and then there is teaching to the exam. Although I think I am teaching creatively and teaching creative independence, there is a point where I contradict myself and say to the pupils but now this isn't independent you do this like this and this is how you do it. (Teacher 3) 
A main contributor to shaping classroom culture was school cultural expectations. All the teachers prior to the research accepted norms set out through their school performativity and accountability cultures. They adapted their personal notions of creative teaching in order to fit into these rules where a performative pedagogic discourse underpinned activity. The teachers considered that failure to perform successfully according to the rules could have profound negative consequences on their professional status, especially in light of performance-related pay:

The problem is not art, the problem is schools' data because everything can be measured and there is the element of power that also signals low trust. We are micro managed by statistics. (Teacher 2)

What I find sometimes happens is that I go back into a kind of narrowing in year 9 [pupils aged 14]. In year 9 you start thinking about preparing for GCSE. I start to think about exam results and performance indicators. (Teacher 4)

I've got each lesson planned, it's rigid, down to what the pupils do. Quiet drawing time, then it's a demo, bit of writing on creative thinking and then they have an outcome. (Teacher 1 )

Because of this, classroom rhetoric became focused on outcome-based approaches. According to Engestrom (1999), the object of activity should not be based on objectives. However, the teachers expressed concerns regarding output modes as being key characteristics of classroom practice. It was the finished artwork that was valorised, marked and graded, with creative artistic process being almost incidental to this. Creative teaching and learning was, on the whole, prescribed and rigidly set against standards. The development and exploration of creativity was therefore redundant and classroom activities often ignored the creative process. This product approach deterred creative approaches and favoured more prescribed teaching and learning. One teacher discussed these output modes, claiming:

I think you can teach to a formula and you get everyone [the learners] doing the same thing. (Teacher 3)

The pedagogy of the teachers, their beliefs, theories, epistemologies, practices and agency were challenged in these situations because of the object-focused, outcome-based approach. This not only affected the teachers' pedagogy, but also directly impacted learners, who became fearful of creative practice. The contradictions present in the classroom created unease. Power and control were devised through school cultural measures of performativity and accountability. The teachers and learners were, as Collingwood (1938) posited, 'encultured', conceiving the classroom through determined suppositions led by cultural and political policies and practices. Although this research aimed to engage teachers in practice that challenged and encouraged creativity, it became evident that transformation could not occur until the teachers recognised that these contradictions existed. Only through recognition could alternative positioning and a reconfiguring of practice occur. In order to take courageous steps towards more creative teaching and learning the teachers needed to develop the confidence to question, be willing to take risks and reflect on practice. 


\section{Aggravating classroom contradictions}

Engeström $(2001,7)$ claims that a person can change an activity system through aggravation, stating:

As the contradictions of an activity system are aggravated, some individual participants begin to question and deviate from its established norms. In some cases, this escalates into collaborative envisioning and a deliberate collective change effort. Activity is reconceptualised to embrace a radically wider horizon of possibilities than the previous mode of activity.

As the teachers' contradictions were historically accumulating, they would not be easily probed. Power had a profound effect on the experience of teachers where identity was put into question. A consequence of a marketised approach to forms of capital was the construction of identity dominated by boundaries (Atkinson 2002). Aggravation began through critical conversations via the post-lesson reflections. As the researcher, I acted as an aggravator, probing perceptions. This was aided by the activity system nodes, which broke down the social, cultural and political contexts of the classroom.

Identity aggravation

Teacher identity is an integral part of the classroom experience, as it is the teacher who stimulates activity. To aggravate identity, the teachers were encouraged to explore their identity via two facets. This began with the exploration of the self, concerning how the teachers perceived their roles within the classroom and their personal philosophies of art and design education. This then moved onto exploring the social self, how they distinguished themselves within the community of the classroom and the culture of the school. 
To help the teachers reflect on their sense of self I asked them to reflect on their creative teaching approaches by exploring their subjectivity. When asked 'What is your role in the classroom?' one teacher replied:

I have realised that I need to step back and think about my role in the learning process. I am an artist and a teacher and therefore should also partake in the process, not just impart knowledge onto the pupils. (Teacher 3 )

Changes in teacher pedagogy effected a transformation of learner understanding and knowledge of creative learning. Utilising AT allowed the teachers to perceive creative teaching and learning as a sociocultural practice. Vygotsky (1978) emphasised the importance of social interactions and how they are constructed through historical and cultural influences. The teachers in this study were enabled through reflection to recognise the classroom as a socially structured space, which included the learners, as one teacher stated:

I need to listen to them (the learners)... (Teacher 4)

As learner identity is embedded in the context, they are co-participants. Therefore a learning environment that is situated (like that of the classroom), is defined by the community's characteristics. Participation in the classroom therefore requires the teacher and learners to 'share understandings concerning what they are doing and what that means for their lives and for their communities' (Fuller \& Unwin 2003, 98).

\section{Division of labour aggravation}

Another factor contributing to creative adaptation in the classroom were changes in power and divisions of labour. Via the activity system, power in the classroom became more collaborative where the learners began to take a greater role. When asked about the divisions of labour within the classroom, one teacher stated:

Since reflecting on my role, the relationship between the class and me grew. I am now able to acknowledge that I not just there to teach them how to be good artists but that's this was a shared process of creative exploration. Not defined by my expectations. I am trying now to create a shared space where I offer more opportunities for the pupils to lead and talk. (Teacher 3)

The new division of labour from teacher-led controls to more collaborative approaches created a mutual meaning-making classroom. For the teachers, this also included an attitudinal transformation where school cultural agents, including policy and school management, became less of a focus for creative teaching and learning. Although the teachers still had to consider school policy, it did not overwhelm the classroom. Performative practices, assessment regimes and formal teaching approaches were left to one side in order to allow creative teaching and learning to develop. Through this, shifts occurred in the types of interactions within the classroom. The classroom became more of a social space that was less about teacher-directed activity but an appreciation of both teacher and learner knowledge. This form of practice 
allowed the teachers to rebalance pedagogy, where the learners worked towards non-prescribed creative outcomes. One teacher noted:

I took a step back, and by doing that the learners were able to communicate to one another and develop their own questioning skills. Through reflection I have learnt to facilitate conversations but not take control of them. (Teacher 1 )

\section{Rule aggravation}

The AT system allowed the teachers to observe practice and critically question beliefs and values regarding creativity. They put aside pedagogies influenced by accountability, performativity and school cultural expectations and re-engaged with their personalised pedagogies. This enabled them to regain power and aggravate notions of pedagogy, stimulate creative knowledge and consider creative teaching approaches, as one teacher noted:

I am beginning to think less about expected outcomes but creating a space for creativity. It feels good to be offered time to consider and think these things, taking a step back and thinking about how I am teaching. (Teacher 4)

This also impacted their perspective of assessment and what they valued as creative learning:

I think I might revise some of my assessment measures and take account of the process as well as the product. I don't think I considered this enough. (Teacher 1)

\section{Object as product aggravation}

Prior to the research, the objects of classroom activity for all the teachers were practically based. The activity system and reflections on creativity enabled the teachers to begin to establish classroom practice based on creative learning processes. This required a renegotiation of classroom objectives, where learning changed from being focused on performative and assessment focused outcomes to creative processes. The teachers began to value, observe and characterise creativity. They recognised that creative outcomes were not created from nothing, but through the connection between patterns of thought and the internalisation of creativity. When asked 'How do you plan for creativity?' one teacher replied:

It is important to re-engage with the process of activity so that they are considered in equal measure to the outcomes. (Teacher 3 )

Because of this new perspective, practice became less focused on performative-measured skill, but a combination of skill alongside creative thinking and behaviour. This new focus was a main contributor for the critical change of assessment practice within the classroom. I asked the teachers about how the assess creative work and they replied: 
The creative connection is as important as skill and that they go hand in hand together'. (Teacher 1)

There is less focus on the outcomes and more on the process. It has made me think less about the importance of a finished piece but that the end outcome is a sequence of creative processes. (Teacher 3 ) This was not an easy or quick transition for the teachers. They found it difficult to aggravate assessment processes, as they had been conditioned into these practices through the historicity of school measures. However, aggravation occurred because creativity was made explicit and the process of developing a creative artwork became more obvious, as described by one of the teachers:

It is important to be reflective on what creative behaviours look like. These reflections assisted my assessments of learners work.

\section{Discussion}

There are many challenges when trying to understand teaching and learning in the classroom where history and context are central to the environment, therefore engaging in this complex environment required not just one way of knowing and valuing. AT was adopted so that attention could be paid to the

systems of activity that occurred in the classroom and which either supported and nourished creative practice or restricted it. The combination of exploring subjectivity, the rules of the classroom, divisions of labour, the classroom community alongside the object of the activity leading to an outcome allowed a multi-layered analysis to take place. By looking at each node of the activity system examination, reflection and questioning occurred. This generated deep reflection on relationships present within the classroom and the top-down and bottom-up structures and patterns of thought which impinged on activity (Welch 2007). Once highlighted, these contradictions were subject to transformation and aggravation which began to enable the teachers to change practice towards more creative forms.

Through the activity system the teachers and I were able to investigate factors impinging creativity but we were also enabled to explore new ways it could be taken forward. There is evidence from using the AT analysis that key changes happened throughout the system. The activity system enables reflection in and on the social, cultural and creative processes within the classroom. This was evidenced by the teachers aggravating daily practices, previously led by the rules of activity, towards new approaches focused on learner-determined creative processes, not outcomes.

Understanding historicity and reflection on this was important for criticality. The teachers needed to evaluate their practices in order to challenge the activity system. Exploring the nodes of the activity system allowed the teachers to examine practice and reconsider how they plan for creativity and collaboration in the classroom. The activity system was valuable for exploring creativity, for the researcher and teachers. Thismakes it a practical yet analytical and critical tool It is hoped that through exploring practice through the activity system the teachers will continue to reflect on practice and utilise the activity nodes as a way to critique practice and explore new approaches to teaching and learning. 


\section{Conclusion}

In this research, AT enabled deeper understanding of creative teaching and learning. It also points ways of developing practice and outlined ways in which a creative pedagogy could be taken forward. A key aspect of this research was the exploration of how researchers and teachers can use AT to access closedoff areas of classroom activities and interactions to reveal underlying classroom ontologies. AT deconstructed the creative process for pedagogic purposes, and broke down teaching and learning into observable components. Pedagogy does not develop easily. However, by using an AT system as an analytical tool, the teachers and I were able to observe, label and discuss practice, leading to change.

The AT methodological framework is not limited to creative activities but open for use across contexts. It can be adjusted to explore educational problems, relationships, cognition and cultural resources that influence change. I would propose that its effectiveness in this research has shown its use for art and design teachers and research within the classroom as a methodological and analytical approach.

Victoria Kinsella is Research Fellow in Education at Birmingham City University, UK. Victoria has researched in the field of the arts education and creativity. She has worked on a number of creative arts projects in various contexts including schools, prisons and with outside educational agencies. Her research interests include the exploration of creative teaching and learning and how we might foster these approaches within educational contexts. She is also interested in cultural historical activity theory for the analysis of learning within the creative classroom. Prior to her academic studies she worked as a teacher in UK secondary schools. Contact address: Centre for Research in Education, Birmingham City University, Rm A025, Attwood Building, City North Campus, Birmingham B42 2SU, UK. Email: victoria.kinsella@bcu.ac.uk 


\section{References}

Atkinson, D. (2003) Forming teaching identities in initial teacher education, in N. Addison \& L. Burgess [Eds] Issues in Art and Design Teaching. London and New York: RoutledgeFalmer, pp. 188-98.

Bakhurst, D. (2009) Reflections on activity theory, Educational Review, Vol. 61, No. 2, pp. 197210.

Ball, S. J. (2003) The More Things Change: Educational Research, Social Class and 'Interlocking' Inequalities. London: Institute of Education.

Beetlestone, F. (1998) Creative Children, Imaginative Teaching. Buckingham: Open University Press.

Blin, F. \& Munro, M. (2008) Why hasn't technology disrupted academics' teaching practices?, Understanding resistance to change through the lens of activity theory, Computers \& Education, Vol. 50, No. 2, pp. 475-90.

Burnard, P. (2007) Reframing creativity and technology: promoting pedagogic change in music education, Journal of Music, Technology and Education, Vol. 1, No. 1, pp. 37-55.

Burnard, P. \& White, J. (2008) Creativity and performativity: counterpoints in British and Australian education, British Educational Research Journal, Vol. 34, No. 5, pp. 667-82.

Butler, J. (1990) Gender Trouble: Feminism and the Subversion of Identity. New York: Routledge.

Collingwood, R. (1938) The Principles of Art. Oxford: Clarendon Press.

Craft, A., et al. [Eds] (1997) Can you Teach Creativity?. Nottingham: Education Now.

Department for Education (DfE) (2010) The Importance of Teaching: The Schools White Paper. London: Her Majesty's Stationery Office.

Engestrom, Y. (1999) AT and individual and social transformation, in Y. Engeström, Y. Miettinen \& R. L. Punamäki [Eds] Perspectives on AT. Cambridge: Cambridge University Press, pp. 19-38

Engestrom, Y. (2001) Expansive learning at work: toward an activity theoretical reconceptualization, Journal of Education and Work, Vol. 14, No. 1, pp. 133-56.

Engestrom, Y., Miettinen, Y. \& Punamäki, R. L. [Eds] Perspectives on AT. Cambridge: Cambridge University Press.

Fuller, A. \& Unwin, L. (2003) Learning as apprentices in the contemporary UK workforce: creating and managing expansive and restrictive participation, Journal of Education and Work, Vol. 16, No. 4, pp. 40726. Geertz, C. (1973) The Interpretation of Culture. New York: Basic Books.

Greene, J. C., Benjamin, L. \& Goodyear, L. (2001) The merits of mixing methods in evaluation, Evaluation, Vol. 7, No. 1, pp. 25-44.

Harland, J., Kinder, K., Haynes, J. \& Schagen, I. (1998) The Effects and Effectiveness of Arts Education in Schools, Interim Report 1. Slough: National Foundation for Educational Research.

Henley, D. (2012) Cultural Education in England. London: DCMS and DfES.

Jackson, P. W., Boostrom, R. E. \& Hansen, D. T. (1993) The Moral Life of Schools. San Francisco, CA: JosseyBass.

Jeffery, B. (2004) Creative Learning and Student Perspectives (CLASP). Swindon: Economic and Social Research Council.

Jeffery, B. \& Woods, P. (2003) The Creative School: A Framework for Success, Quality and Effectiveness. Abingdon: RoutledgeFalmer.

Leont'ev, A. N. (1978). Activity, Consciousness and Personality. Englewood Cliffs, NJ: Prentice Hall. 
Maisuria, A. (2005) The turbulent times of creativity in the national curriculum, Policy Futures in Education, Vol. 3, No. 2, pp. 141-52.

NACCCE (1999) All Our Futures: Creativity, Culture and Education. London: DfEE.

Russell International Excellence Group (2011) Informed Choices: A Russell Group Guide to Making Decisions post-16 Education. London: The Russell Group.

Schon, D. (1983) The Reflective Practitioner: How Professionals Think in Action. New York: Basic Books. Seltzer, K. \& Bentley, T. (1999) The Creative Age: Knowledge and Skills for the New Economy. London: Demos.

Starko, A. J. (2005) Creativity in the Classroom: Schools of Curious Delight. Mahwah, NJ: Lawrence Erlbaum.

Steers, J. (2010) A return to design in art and design: developing creativity and innovation, in N. Addison, I. Burgess, J. Steers \& J. Trowell [Eds] Understanding Art Education: Engaging Reflexively with Practice. London: RoutledgeFalmer, pp. 24-40.

Turner-Bisset, R. (2007) Performativity by stealth: a critique of recent initiatives on creativity, Education 3-13, Vol. 35, No. 2, pp. 193-203.

Vygotsky, L. S. (1978) Mind in Society: The Development of Higher Psychological Processes. Cambridge, MA: Harvard University Press.

Welch, G. F. (2007) Addressing the multifaceted nature of music education: an activity theory research perspective, Research Studies in Music Education, Vol. 28, No. 23, pp. 23-37.

Woods, P. \& Jeffery, B. (1996) Teachable Moments: The Art of Creative Teaching in Primary Schools. Buckingham: Open University Press. 